\title{
Effective Change Management for Sustainable Development in Higher Education Institutions
}

\author{
Yehualashet Getahun Ayele \\ School of Commerce, Addis Ababa University, PO box 1176, Addis Ababa, Ethiopia
}

\begin{abstract}
This study scrutinized the prevailing platform wherein change management is being practiced in Ethiopian Higher Education Institutions (EHEIs) as per the theoretical argument of implementing change programs with their long-term consequences in mind. In this study the researcher investigated the change management protocol of Ethiopian Higher Education Institutions (EHEIs) since the education sector is identified as the key to unlocking the economic potentials of the country. However, the sector is earnestly constrained by a number of factors which include, but not limited to, poor change management protocols. Hence, in this study the researcher aspired to make a theoretical contribution to the body of knowledge related to change management protocols in EHEIs. In view of that, this research is fundamentally designed to observe the change management protocol of EHEIs; and put forward change management practices that bring about sustainable development in the institutions and beyond. Thus, the study primarily focused on identifying effective leadership styles to be followed during periods of change and how it can generate positive change that helps the attainment of sustainable developmental goals in EHEIs. The paper also discussed leaders' roles and deeds for effective management of change. A qualitative approach based on an extensive review of relevant literature is used to draw conclusions and recommendations. Accordingly, comprehensive enquiry of the data collected for the purpose of this study revealed that the development of new knowledge or insights that have the potential to influence behavior is the most important success factor for effective sustainable development. On the other hand, failure to progressively institutionalize change initiatives is the core cause why change initiatives often fail in EHEIs. The research findings, therefore, disclose that organizational learning should take place within the wide institutional context of inter-organizational relationships and an organization's acquisition of understanding, know-how, techniques and practices of any kind of change and by any means need to be stimulated. Conclusively, the paper stresses that effective leadership is the key to success of every organization, for EHEIs to achieve sustainable development, the senior management of the institutions have greater role to play. Turning institutions to learning organizations and adoption of transformational leadership style are recommended for effective change management process.
\end{abstract}

Keywords: Adaptation, Change Management, Organizational Learning, Organizational Leadership, Sustainable Development

DOI: $10.7176 / \mathrm{EJBM} / 12-10-01$

Publication date: April $30^{\text {th }} 2020$

\section{1) Conceptual definition of terms}

This section of the document portrays the conceptual definition of some attention worthy terminologies used throughout this paper:

Change: Transformation, modification, alteration, amendement. (Oxford dictionary)

Change Management: refers to any approach to transitioning individuals using methods intended to re-direct the use of resources, business process, budget allocations, or other modes of operation that significantly reshape a company or organization. (Wikipedia)

Organization: A social unit of people that is structured and managed to meet a need or to pursue collective goals (http://www.businessdictionary.com/)

Organizational change management: refers to managing change in an organization (http://www.businessdictionary.com/)

\section{2) Background of the study}

In this era of globalization change has become a common scenario organizations experience every now and then. The rapid growth of the economic environment as well as the emergence of the internet made it easier to communicate with countries around the world. This in turn changed the business environment in every country, causing competitiveness in the market that increases with each passing year (Friedman, 2007). Hence, a change introduced on one side of the world instantaneously impacts the other extreme of the globe. Thus, nowadays, waves of change have been everywhere. In the light of this, our era is a time of unprecedented change in our society. The changes one experiences are happening at faster and faster rates. As examples, the telephone, radio, $\mathrm{TV}$, and microwave weren't even in use decades ago, and today these gadgets are commonplace, along with the computer, Internet, and fax machine. Change doesn't change; and is unavoidable. This has amplified the 
importance of introducing structural change management.

Organizational norms, cultures, procedures and courses of actions get out-dated at an alarming rate due to the emergence of new trends in the daily lives of individuals. This adaptation from time-honoured to novel ways of getting things done is a process that can simply be referred to as change. These unavoidable changing situations in individuals' lives and business undertakings require the right management and proper handling so as to secure sustainable development and prosperity. Thus, to successfully adopt and implement change, communicating the theme of the change and its ultimate objective to the right human capital of the institutions is critical. The 'right people' have a massive impact towards successful implementation of change. (Jim Collins, 2000). A properly communicated change process overcomes the barrier of resistance by 'redesigning' a people's attitude. It begins by restoring a sense of security based on the impacts of change, for example in terms of layoffs or a switch in positions and job security in general. Proper management process will explain the need for change, why there is need to break the odds of the status quo and the benefits attached to that change. The positive side of it is of the fact that employees will provide full support for the program (Scott \& Bruce's, 1994). Effective management demands heightened leadership and change management expertise to motivate and unite people behind the new change introduced and to ensure continuous alignment of core teams with strategic goals. In this era of scarce resources, tight deadlines, ever-changing environments, demanding customers, tough regulatory regimes, and alert public scrutiny, leadership skills of leaders play a pivotal role in inspiring success across all spheres of the institute.

\section{3) Why change management?}

In just a few months, the technology that an institute uses on an everyday basis may be out-dated; and the organization may be forced to replace it. That means an institute needs to be responsive to changes in its internal and external environments. At one fell swoop, its employees' work skills must change as the working environment changes. Institutions that refuse to adapt to change are likely to be the ones that won't be around in a few short years. If an institute wants to survive and prosper, its managers must continually innovate and adapt to new situations.

Change has always been an issue for organizations, just as it has always been a common characteristic of human life. Change is definitely hard for humans to accept as it is something that pull people out of their comfort zones, which forces them to change their habits and makes them highly uncomfortable (Lorenzoni, Nicholson, and Whitmarsh, 2007).

Every institute goes through periods of transformation that can cause stress and uncertainty. Yet to be successful, institutes must embrace as many types of enlightened changes as possible. Institutions must also develop improved working culture, create new working frameworks and course of action, implement new administrative systems, upgrade employees' skills, and shape community attitude. Institutes that adapt successfully are both profitable and admired.

With this in mind, this research addresses the importance of change management in order to create institutes that have the ability to set aside old ways of thinking, the desire to become self-aware and open, the opportunity to learn how the whole institute works, and the commitment to develop a plan of action and work as a unit to accomplish the plan.

To end with, in this study the Change Management of Ethiopian Higher Education Institutions (EHEIs) is discussed. The researcher believes that change management is critical to institutes' success in today's highly competitive and vibrant business environment. In the light of this, in this study the Change Management practices of EHEIs are examined. In the meantime, it is also worth mentioning that Change Management as a discipline within management is one of the least researched and least discussed topics in professional journals and books focusing on management. Thus, there is a need for research to fill this gap. This is the most imperative reason that made the researcher to choose change management as subject of this study.

\section{4) Statement of the problem:}

As the old saying goes, "Everything changes, but change." In this day and age, Ethiopian higher education institutions are functioning in extremely unpredictable and impulsive working environment that may change spontaneously. Subsequently, the art of change management has become the most important managerial dexterity that determines the success or failure of the change introduced. In view of that, change management in an organization can be defined as an approach to deal with change in the organization (where the change is being made) and the individual (affecting or affected by the change process), with individuals and the overall organization adapting to change at their own pace and style. Change management allows institutions to catch an opportunity to gain a competitive advantage, if the organization effectively and efficiently implements and adapts to the change made.

Different people react to change differently. Good change managers pay good attention to change preferences of their followers, and as a result they can better understand why people react the way they do when 
faced with change. These managers are more prepared to address concerns, leverage different contributions, avoid pitfalls and adapt their own change approach as needed. Eventually, they are also the ones who harvest the upshots of the effective change made.

The dynamics of management leading the change can either contribute to the negativity or turn a negative situation into positive with winning results for the organization as a whole (Stensaker, et al., 2012). For managers attempting to help their organization through a major process that will affect employees, it is important for management to be visible in the office environment and measure the attitudes, beliefs, and values of their population, which is usually best done using surveys (Whyte, 1991). The surveys give management a view of how employees currently envision the idea of change before the change is implemented. When there is a change process in an organization, the challenges and the goals to be carried out may not be fully accomplished if those who are expected to carry out the goals are not included in the decision making (Whyte, 1991). Sagie and Koslowsky (2000) stated "The gap between the failure of management plans and their success may, therefore, be a function of the gap between worker resistance to and acceptance of these plans" (p. 19). The employee resisting change can be a troubling problem, sometimes more so than the complication of learning new technology.

Thus, painstaking change management schemes will help to minimize resistance to change and support to maintain industrial peace. However, if change implementation process is not properly managed, industrial peace and people's peace of mind will be apprehensive. This, in turn, results in resistance to change and job dissatisfaction on the side of individuals and groups affected by the new change made. Likewise, today's Ethiopian Higher Education Institutions (EHEIs) are suffering from the downsides of poor change management practices. Nowadays, instability has become the spitting image of these institutions. Accordingly, the problem statement for this study is to investigate the change management schemes of EHEIs and their short and long term consequences. Most importantly, this study answers the question "Does the management of EHEIs realize that serious underlying problems prevailing in change management practices of the institutions ought to be addressed with long-term consequences in mind?"

\section{5) Basic research questions:}

For the successful achievement of the research objective, two sets of questions were used: Foundation or core research question and sub questions. The core research question is indicative of a critical case in which a wellformulated theory is tested, and the propositions of the circumstances around it are understandable and believed to be true.

In this study, the core research question is "Do change agents of Ethiopian Higher Education Institutions (EHEIs) address change with its long-term consequences in mind?"

To support the above-mentioned core research question and better examine the matter under investigation, the following sub questions were designed and used.

1) What drives EHEIs to introduce changes in their day-to-day undertakings?

2) How meaningful are the changes made?

3) What are potential success factors and pitfalls in the art of change management?

4) Do stakeholders at different levels of the institutions take part in the change development process beginning from its inception?

5) What factors are assumed to affect the change management endeavour of the institutions?

6) Does the change management process affect:

$\checkmark$ subsequent operations of the institutions?

$\checkmark \quad$ industrial peace of the institutions?

7) Is there any difference in the working environment of the institution before and after the intended change is introduced in the institutions, other than the change itself?

8) What is the management's perception on the effect of the change management process on subsequent undertakings and industrial peace of the institution?

\section{6) Objectives of the study:}

6.1 General objective:

The general objective of this study is to scrutinize the prevailing platform wherein change management is exercised in Ethiopian Higher Education Institutions in an attempt to implement change programs with their long-term consequences in mind. In addition, the difference between the working environment of the institutions before and after the introduction of changes will be pointed out, if any.

\subsection{Specific objectives:}

So as to achieve the above general objective of the research worthily, a series of specific objectives have been designed. Accordingly, in this study the researcher strived:

(1). To ascertain factors that force EHEIs to introduce changes in their day-to-day undertakings. 
(2). To examine basic features of changes made in these institutions every so often.

(3). To identify potential success factors and pitfalls in the art of change management.

(4). To inspect if pertinent stakeholders (particularly employees) were involved in the change management process of the institutions.

(5). To pinpoint elements that may affect the change management endeavour of the institutions.

6. To identify factors that affects the plan and implementation of change management in EHEIs.

(7). To inspect the effect of the change management process on subsequent operations of the institutions.

8. To assess the upshot of the change management process on industrial peace of the institutions.

(9). To appraise differences, if any, in the working environment of the institutions before and after the intended change is introduced.

(10). To uncover the management's perception on the effect of the change management course of action on subsequent undertakings and industrial peace of the institutions.

\section{7) Significances/Benefits of the study:}

Change Management is a common word in today's businesses. With constantly evolving business goals and strategies, change is inevitable and managing change is essential. Change management is also used as a catch-all for business activities that may otherwise be overlooked. It is thus important to understand what it is and how to use it to be effective in the discipline (Warwick, 1975).

On account of overwhelming advancements and immense innovations, institutions have become increasingly open and responsive to changes to support their business process and decision making. Should institutions do not give due attention to changes in their business environment, the inevitable impact of these changes is likely to drive them out of operation. Changes in the business environment may adversely affect the competitive success of institutions. Without a doubt, poor change management adversely damages industrial peace and distracts regular work flow. Above all, there are severe drawbacks of change management. Perhaps, if the management of an institute takes no notice of a new industrial policy enacted by the government and declines to respond to the change, sooner or later the management will face the downside of its decision. What is even more important is the downside of refusing to act on changes of this kind may be as worse as exposing the institute to legal accountability, perhaps loss of its legal personality for not abiding by law. This, among others, noticeably marks the need to research the change management practice of institutions.

It is important to note that 'institutions' are not the ones that change; it is the people within institutions that change. Therefore, the success of institutions is ultimately measured by the difference in work done by each individual employees impacted by the change. Consequently, effective change management requires an understanding for, and appreciation of how one person makes a change successfully. Without an individual's constructive perspective of the change anticipated, change management amounts to activities performed without goals or outcomes achieved (Bourda, 2005). In effect, working on individuals' perspective of change concludes the entire change management effort of institutions.

In these days highly competitive and vastly changing environment, speed and flexibility are essential. The most successful organizations in the long run are those who continuously adapt to changes in their environment (Sauser \& Sauser 2002, p. 34). The rate at which individuals and organizations adapt and learn may become the only sustainable competitive advantage, especially in knowledge-intensive industries (Stata 1989, p. 64; Rothwell et al. 2000, 54; Dale et al. 2013, p. 202). Thus, organizations cannot ignore that a great deal about adding value comes from ensuring an effective and sustainable management of change (Paton \& McCalman 2000, p. 38).

In today's vigorous business environment, organizational changes and methods of addressing them are prevalent as we seek to stabilize and sustain transformation across locations. The way institutions manage change and how successful they are at it, largely determines the future fate of the institutions. Therefore, the study of how well the institutions and people understand the need for the change and the process involved in it is a milestone in leading change agents through the change process.

Applying change management activities can be instrumental in realizing goals for planned and unplanned changes both internally and externally. It also helps diagnose problems associated with the transition before they become a crisis. Therefore, it is essential to first understand the art of change management before a change becomes a crisis.

In brief, this research fills the knowledge gap perceived on change management practices of most institutions. These days, as institutions are functioning in a world of continuous change, change management skills have become key success factors of daily business deals. "In the world of business, change is the only constant. Master it." (Rotterdam School of Management, Erasmus University 2015). Change is expensive, but to refuse to adapt to change is even more expensive. Thus, the only choice institutions have these days is to respond to changes as they come about. Hence, change is constant; and needs to be supported with brilliant change 
management protocols that are identified through research findings. Unfortunately, change management (particularly in higher education institutions) is the least researched area in the discipline of management. Therefore, this study fills the research gap, and plays its part in guiding future researchers in the area.

Likewise, the research findings guide experts through their change management efforts. This, in turn, increases the success rate of changes made by these institutions. It is also worth mentioning that the findings of this study are likely to be extended to institutions of similar dynamism with the institutions set aside for consideration in this study. Finally, without a shadow of doubt, the findings of this research will have practical significances.

\section{8) Research methodology:}

Change is a complex phenomenon, change management is even more. Therefore, the researcher believes that wise decision should be made on the choice of the research approach in order to be able to investigate this complex phenomenon and achieve the research objective as planned. Thus, to better embark on the research objective, a qualitative case study approach is employed accompanied by one-to-one focused interviews. Case study approach is utilized for intervening in a change management situation and grasp hands-on experience from it. This approach also helps to evaluate a changed process for effectiveness and efficiency. Besides, interviews offer an opportunity to learn and explore why a particular process is occurring or has occurred. Yin, G. (1994) stated that interviews are a vital source of evidence for case study research because this type of research involves humans and their behavior regarding the events in question.

Research participants were chosen from different classes of the institutions' community. This community includes management members, instructors, support staffs, students, government representatives at different levels, and dwellers of the vicinity. Besides, both random and non-random sampling techniques were employed (as appropriate and as called by situations) to help the researcher better uncover circumstances and identify factors impacting the change management process. The duration of the study encompassed two years.

\section{9) Major research findings:}

The most attention worthy finding of this research is that change is often initiated by the management of the institutions or the government without involving other interested parties, particularly employees and students. Thus, most key stakeholders are usually not a part of the process in any new or upgraded system implementation that directly affects their job and lives. The research also revealed that when handling organizational change, management usually decides how a change will take place and what method will be used to incorporate the change, without involving these interested parties.

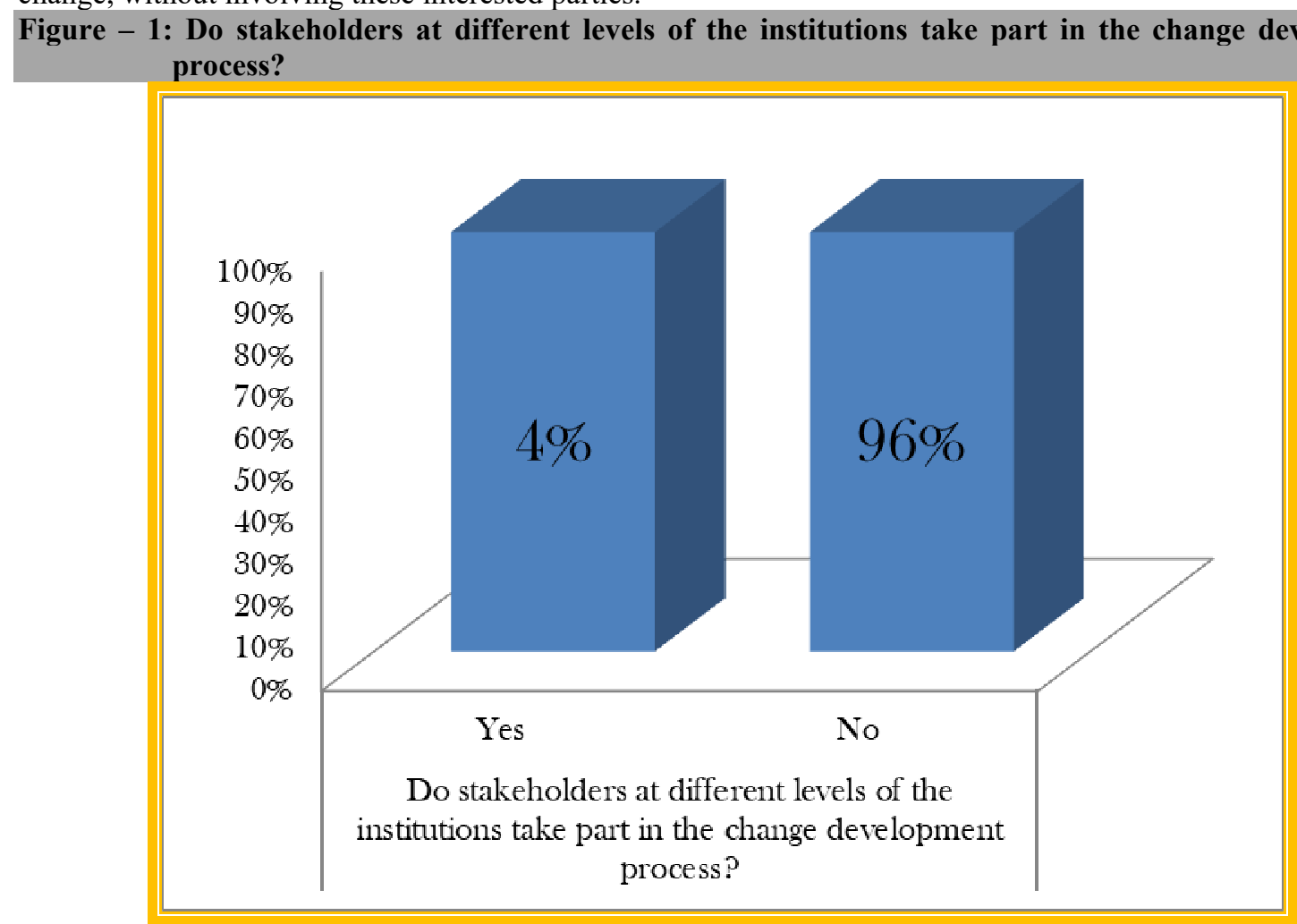

(Source: Own Survey) 
Nevertheless, 'involvement in the change process' belonged to one of the most vital success factors mentioned by most respondents in this research and thus possesses high importance in change management. In view of that, the overall findings of the research revealed that people accept changes better when asked by management to be a part of the change process. Some stakeholders felt management did show concern for their ideas and opinions by acknowledging them at meetings set up between management and the stakeholders about the change implementation process. Yet, there were some group of people who still felt as if management did not do enough or provide appropriate training to engage them in the change process. Surprisingly enough, these people exhibited strong resistance to the change process. To make the matter even worse, often they form informal groups in the institutions and obliterate social ties among the community of the institutions. This, in turn, caused absence of industrial peace in the institutions and beyond. Likewise, the motivation, commitment and attitude of those who didn't get involved in the change management process were found to decline as never before. In the same way, the performance of employees and students went downhill and a high employee turnover rate was recorded. In conclusion, the findings of this study publicized that stakeholders' involvement provides a sense of value and is crucial for successful change management practices.

Table - 1: Stakeholders" "Sense of belongingness" and "Resistance to change" versus their "Involvement in the change process"

STAKEHOLDERS

Sense of belongingness

Resistance to change

\begin{tabular}{|l|c|c|}
\hline Involved in the change process & $100 \%$ & $0.5 \%$ \\
\hline Not Involved in the change process & $0 \%$ & $100 \%$ \\
\hline
\end{tabular}

(Source: Own Survey)

Moreover, this study discovered that a clear purpose and process of change management is another decisive success factor. Accordingly, for effective change management, the purpose and process of the change should be communicated to those affected by it for them to develop good perception to the change to be made. People mainly change when it makes sense; and this is accomplished only through effective communication.

Figure - 2: Response to change when its purpose and process are properly communicated

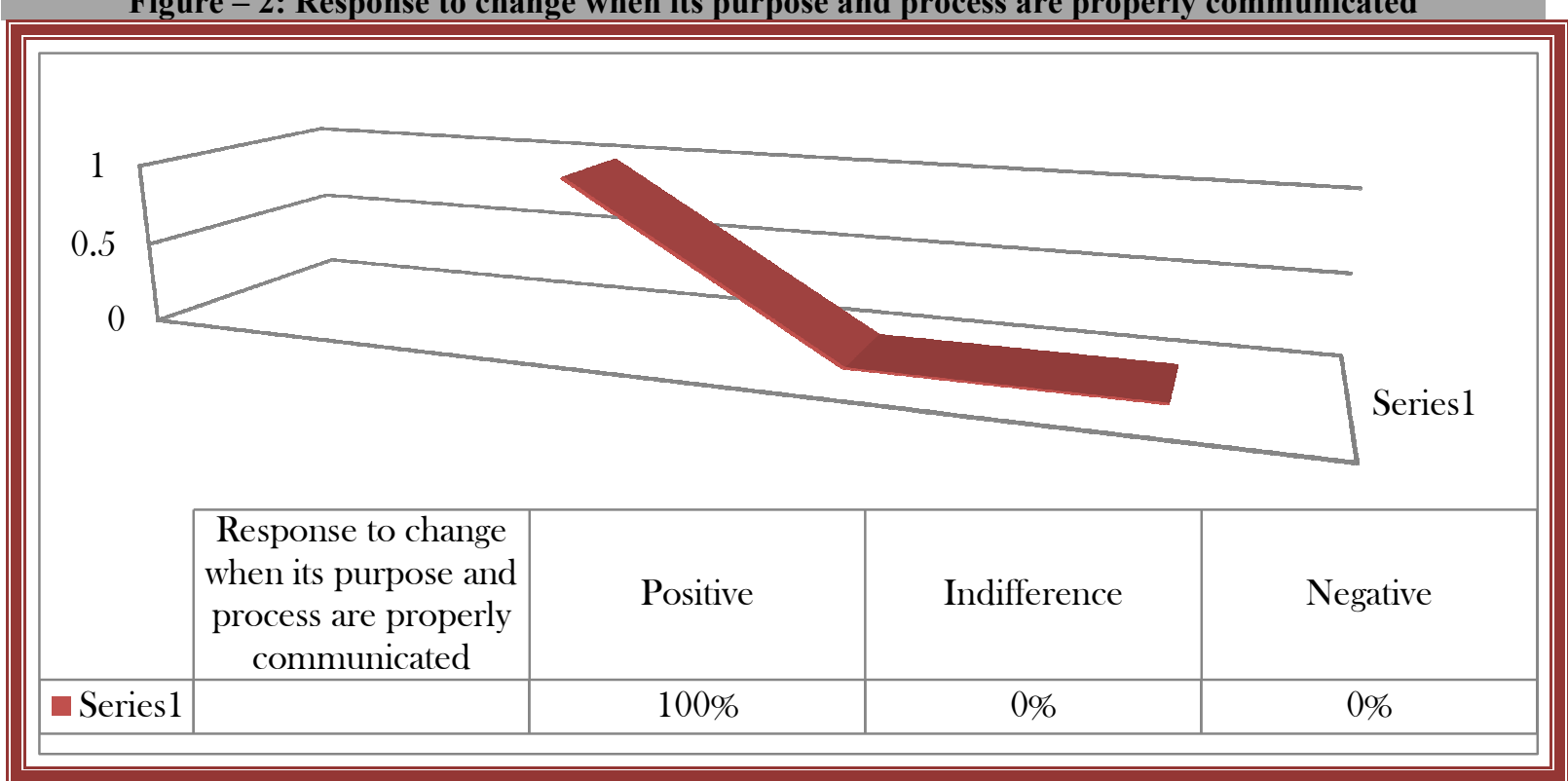

(Source: Own Survey)

On the other hand, even though there seems to be some inconsistency about the success factors of change management, there are several success factors that appear in the responses of most respondents more often than others. These success factors include presence of clear vision, two-way communication, team spirit, situational leadership, and stakeholder management. People-related factors like diversity also play a crucial role.

Dynamism and responsiveness to change were mentioned by $98 \%$ of the respondents as the two most important qualities of today's businesses to enable them to better serve the developing customer needs and survive in this dynamic business environment. Managing change as well as developing organizational change capacity was pointed out as the other essential quality of today's institutions to institutionalize change. Therefore, in order to be able to institutionalize change in the institutions, change leaders have to be gradual in their process, ensure that prior preparations are well taken care of and appropriate leadership style is exhibited. The first priority of change leaders before implementing change is to ensure they turn their institutions to learning organization. 


\section{Change Management Success Factors}

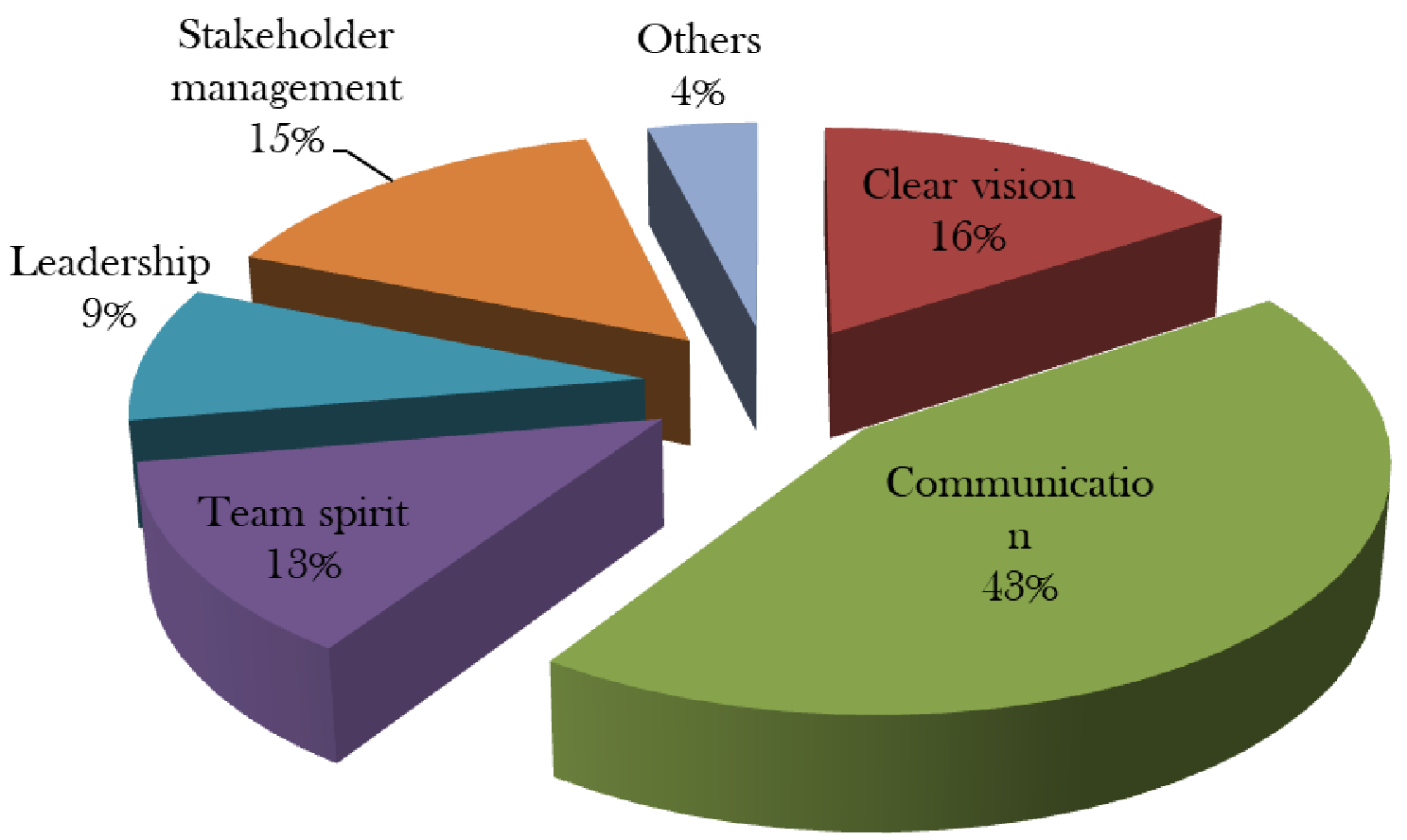

(Source: Own Survey)

\section{0) Conclusion}

In this study the researcher strived to provide a deep insight into the broad topic of change management as practiced in Ethiopian Higher Education Institutions. Plentiful evidences collected for the purpose of this study also indicated that the change management practices of most of the institutions is much below expectations, leading them to high failure rates, deprived motivation and industrial instability. Thus, it is barely possible to bring about successful changes without intense involvement of individuals and groups affected by the change. Hence, all interested parties should be heard; and their interests should be taken into consideration when managing change for it to succeed.

On the other side of the spectrum, leaders of Higher Education Institutions have to initiate series of change programs in order to keep on living in the contemporary societies. The change initiatives will enable them to be relevant, as well meet the need of the society. However, the change initiatives should not be haphazardly carried out. This highlights the indispensable role of change management. Furthermore, this paper revealed that the progression of change initiatives depends on how well the leaders are able to prepare themselves and their institutions for the change program initiated.

To sum up, this research divulged that since a recipe for successful change management does not exist, it is impossible to fully control change by predefined change plan. Instead, understanding the complex and multifaceted character of change is decisive. Hence, it seems based on this research that all individuals and groups affected by or affecting the new change should be involved in the change management process for them to own the change and make it effective.

\section{1) Recommendation}

Briefly, the researcher of this study recommends the following schemes for both future researchers and 
practitioners in the area.

Change management protocols ought to involve all stakeholders beginning from the inception of the change notion. This helps institutions to lessen resistance to change, thereby successfully instituting change management in the institutions.

Change management should be a structured approach in order to bring about the desired change as premeditated, and harvest long-lasting benefits of the change.

Change leaders must first create learning institutions. A leader in a learning institution can easily motivate and influence the people of the institution and apply effective changes to the institution.

Finally, the researcher recommends the replication of this research in various dynamisms, in terms of both scope and sector.

12) References

1) Bourda (2005) Change management theories and methodologies: The use of change management, CIMA Publishing, United Kingdom.

2) Brenner, M. (2008). It's all about people: change management's greatest lever. Business Strategy Series, 9(3), 132-137. doi: $10.1108 / 17515630800873366$

3) Dale, B. G., Van Der Wiele, T., \& Van Iwaarden, J. 2013. Managing quality. John Wiley \& Sons. 202 p.

4) Friedman, B. A. (2007). Globalization implications for human resource management roles. Employee Responsibilities and Rights Journal, 19(3), 157 - 171

5) Lawler, A. \& Sillitoe, J. (2010). Perspectives on instituting change management in large organisations. Australian Universities' Review, 52(2), 43-48.

6) Lorenzoni, I., Nicholson-Cole, S., \& Whitmarsh, L. (2007). Barriers perceived to engaging with climate change among the UK public and their policy implications. Global environmental change, 17(3), 445-459.

7) Paton, R. A. \& McCalman, J. 2000. Change Management: A Guide to Effective Implementation. 2nd edition, London, SAGE Publications. 280 p.

8) Rothwell, W. J., Stavros, J. M., Sullivan, R. L., \& Sullivan, A. 2009. Practicing organization development: A guide for leading change. Vol. 34. John Wiley \& Sons. 3rd edition.

9) Rotterdam School of Management, Erasmus University 2015. Masters Programmes 2016- 2017. Rotterdam. URL: http://www.rsm.nl/fileadmin/Images_NEW/Master/Brochure_RSM_Master_Programmes_2016_2017.pdf. Accessed: 10 July 2016.

10) Sagie, A., \& Koslowsky, M.. (2000). Participation and empowerment in organizations: modeling, effectiveness, and applications. Thousand Oaks, CA: Sage Publications.

11) Sauser, W. I., \& Sauser, L. D. 2002. Changing the way we manage change. SAM Advanced Management Journal. Vol. 67. No. 4. pp. 34-39.

12) Stata, R. 1989. Organizational learning - the key to management innovation. Sloan Management Review. Vol. 30. No. 3. pp. 63-74.

13) Stensaker, B., Sarrico, C., Välimaa, J. (2012). Managing Reform in Universities: The dynamics of culture, identity and organizational change. New York, NY: Palgrave MacMillian.

14)Warwick, D. P. (1975) A Theory of Public Bureaucracy. (Cambridge, MA: Harvard University Press) Robinson, s. (1996) 'Trust and the breach of the psychological contract', Administrative Science Quarterly, 41

15)Whyte, W. (1991). Social theory for action: How individuals and organizations learn to change. Beverly Hills, CA: Sage Publications.

16)Yin, G. (1994) Information system development in the small firm: The use of management accounting, CIMA Publishing, United Kingdom. 